\title{
The Influence Of Prospect Theory And Psychological Commitment On The Tax-Reporting Aggressiveness Of Professional Tax Return Preparers
}

Timothy R. Koski, (E-mail: tkoski@usi.edu), University of Southern Indiana Craig R. Ehlen, (E-mail: cehlen@usi.edu), University of Southern Indiana

\begin{abstract}
According to prospect theory (Kahneman and Tversky 1979), decision makers perceive outcomes as gains or losses from a reference point and behave differently depending on how the outcome is framed. Decision makers will be risk-averse if the perceived outcome is viewed as a gain and riskseeking if it is perceived as a loss. Research applying prospect theory to the decision-making of tax preparers by using their client's year-end payment status as the reference point has not been successful (see e.g., Duncan et al. 1988; Sanders and Wyndelts 1989; LaRue and Reckers 1989). One possible explanation for the lack of consistent results in this area is that tax preparers do not internalize the framing of their client's payment status and thus do not have a psychological commitment to the decision outcome. It is the client who is in a gain or loss position, not the tax preparer.
\end{abstract}

This paper reports the results of an experiment applying prospect theory and psychological commitment to tax preparer decision-making. We hypothesized that tax preparers' personal involvement in placing their client in a particular year-end tax situation (payment due or refund) will cause them to use the client's year-end payment status as the reference point and to behave in a manner consistent with the predictions of prospect theory. In particular, we hypothesized that personal involvement in placing their client in a year-end payment due situation will cause tax preparers to frame the decision as a loss and thus behave in a risk-seeking manner. We also hypothesized that personal involvement in placing their client in a year-end refund situation will cause tax preparers to frame the decision as a gain and engage in more risk-averse behavior than tax preparers not so involved.

Using a sample of 104 professional tax return preparers, we found no evidence that psychological commitment to their client's year-end payment status caused tax preparers to behave in a manner consistent with prospect theory. We did, however, find evidence that more experienced tax preparers took more aggressive tax-reporting positions than those with less experience. We also found that males took more aggressive tax-reporting positions than females.

\section{Introduction}

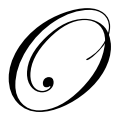

ne of the major theories used to examine the decision-making of tax preparers is prospect theory (Duncan et al. 1988; Sanders and Wyndelts 1989; LaRue and Reckers 1989; Newberry et al. 1993; Schisler 1994). Kahneman and Tversky (1979) proposed prospect theory as an alternative to expected utility theory (von Neuman and Morgenstern 1944). According to prospect theory, decision makers code outcomes in terms of gains and losses from a reference point, rather than final states of wealth (as assumed by expected utility theory). The value

Readers with comments or questions are encouraged to contact the authors via email. 
function applied to possible outcomes is an S-shaped curve that is concave for gains and convex for losses. In addition, the slope of the value function is steeper for losses than for gains, as indicated in Figure 1.

Figure 1 - Value Function

Value

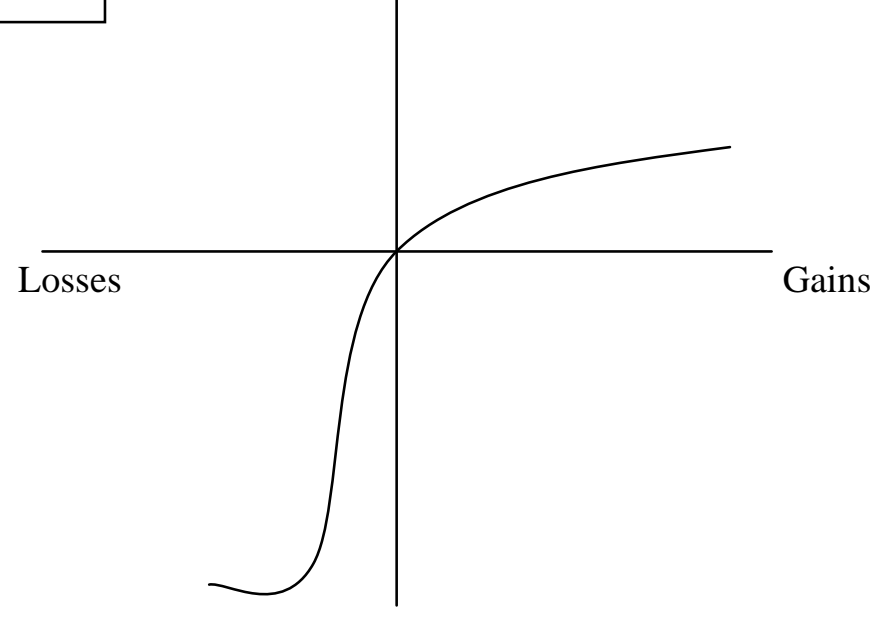

Prospect theory predicts that decision makers will behave differently depending on whether an outcome is framed as a gain or a loss. Because of the slope of the value function, decision makers will be risk-averse in gain situations, and risk seeking in loss situations.

\section{Taxpayer Decision-making}

Research applying prospect theory to taxpayer decision-making typically has used year-end payment status as the reference point (see e.g., Chang et al. 1987; Schadewald 1989; Schepanski and Kelsey 1990; White et al. 1993; Chang 1995; Dusenbury 1994; Schisler 1996). Taxpayers who owe an additional amount of taxes at the end of the year (a tax due situation) are said to be in a loss position. Prospect theory predicts that these taxpayers will be risk-seeking and therefore more willing to take aggressive tax positions. Taxpayers who expect to receive a tax refund at the end of the year (a refund situation), on the other hand, are said to be in a gain position. Prospect theory predicts that these taxpayers will be risk-averse and therefore not as likely to take aggressive tax positions.

Although the results of these studies are not completely consistent, there is substantial evidence that taxpayers behave in a manner consistent with prospect theory when year-end payment position is used as the reference point. Taxpayers in a year-end tax payment position generally are more aggressive in tax reporting positions than taxpayers in a year-end tax refund position.

\section{Tax Preparer Decision-Making}

Research testing the predictions of prospect theory on the decision-making of tax preparers has been less successful than that conducted on taxpayers. A number of studies have used the year-end payment status of the client as the decision frame. A tax preparer with a client in a tax due position is viewed as being in a loss position and is predicted to be risk-seeking. A tax preparer with a client in a tax refund position is viewed as being in a gain position and is predicted to be risk-averse. Studies that have manipulated the decision frame in this manner have achieved mixed results.

Duncan et al. (1988) used an ambiguous depreciation deduction situation to examine the effects of the probability of an IRS audit, risk preference of the client, and year-end payment status of the client on the income reporting recommendations of tax professionals. Duncan et al. (1988) found weak $(\mathrm{p}=.059)$ support for the predictions 
of prospect theory. Tax preparers adopted more aggressive positions when the taxpayer was underpaid and less aggressive positions when the taxpayer was overpaid. Contrary to Duncan et al. (1988), however, Sanders and Wyndelts (1989) and LaRue and Reckers (1989) found no evidence in support of prospect theory when the year-end payment position of the client was used as the reference point.

One possible reason for the inconclusive findings in the tax preparer area is that tax preparers do not have anything directly at stake in a client's prepayment position. It is the client taxpayer who is in the tax due or tax refund position, not the tax preparer. Although a zero payment position is a logical reference point for taxpayers to use, it may not be a logical reference point for tax preparers. Tax preparers may not view a client's additional payment or refund as the preparer's loss or gain. In addition, a tax preparer is more likely to be aware that it is the total amount of taxes, not the balance due at the end of the year, that has the most impact on a client's overall wealth. This explanation, although not conclusive, is consistent with research that has found evidence in support of prospect theory in situations where the tax preparer can be viewed as having a more direct stake in the client's payment status (e.g. Schisler 1994; Newberry et al.

1993).

It is possible that the lack of consistent results in studies applying prospect theory to tax preparer decisionmaking is caused by the tax preparers' failure to frame a client's tax due position as their own loss. The tax preparers do not internalize the client's situation. As Kahneman and Tversky (1981, p. 458) stated, "The framing of acts can also reflect acceptance or rejection of responsibility for particular consequences and the deliberate manipulation of framing is commonly used as an instrument of self-control.”

\section{Psychological Commitment}

The psychological commitment literature has dealt primarily with the issue of whether personal involvement in a course of action causes decision makers to escalate their commitment to a failing course of action. Staw (1976) found that subjects who were responsible for the initial decision to commit resources to a failing project subsequently tended to commit more resources to the project than subjects who were not personally responsible for the initial investment decision. Since Staw's (1976) initial research, this sunk cost effect has been found in numerous settings, and it is a wellestablished phenomenon that decision makers tend to escalate their commitment to a failing course of action for which they are responsible.

Although the precise explanation for escalation of commitment remains controversial (Brockner 1992), one of the most frequently cited explanations for the sunk cost effect is self-justification or rationalization. Decision makers seek to rationalize their previous behavior or to defend themselves psychologically against adverse consequences by increasing commitment to the previous failing course of action, even if they would otherwise not pursue such a course of action (Staw 1976). Because people do not like to admit that their past decisions were incorrect, they seek to reaffirm the correctness of their past decisions by becoming more committed to them (Brockner 1992).

Self-justification can take the form of committing additional resources or risking additional errors (Whyte 1986). The willingness to increase risk in order to justify a previous course of action to which one is psychologically committed is particularly relevant to tax preparers. Tax preparers frequently make recommendations to clients after considering tax-reporting positions with varying degrees of risk. A tax preparer may be willing to accept more risk (by taking a more aggressive tax position) than he or she otherwise would in order to justify a previous decision (or tax estimate) that later proves to be incorrect.

\section{Relationship of Prospect Theory to Psychological Commitment}

This research uses both prospect theory and psychological commitment to study the decision-making of tax preparers. We propose that psychological commitment plays an integrated role in determining how a decision maker frames a particular decision. We hypothesize that a decision maker will be more likely to frame a decision as a loss, and therefore be risk-seeking, when he or she is psychologically committed to a previous decision. The viability of such a proposal is hinted at by Whyte (1986, p. 316), who asserts that, under a prospect theory analysis, sunk costs are relevant only insofar as they influence the framing of decisions: 


\begin{abstract}
It is conceivable that reluctance to accept the reality of negative results, for the reasons suggested by Staw, may retard the process of adaptation to losses. Thus, the establishment of a new account for a decision may not occur when it should, leading to the use of existing accounts which have already been used to record outcomes.
\end{abstract}

In other words, because the personal attributes of the decision maker influence the framing of decisions, a situation where the decision maker is psychologically committed to a failing course of action causes him or her to seek to justify that action and leads to the use of the existing account. The existing account includes the failing course of action, which places it in a loss position. Thus, the decision maker will frame the decision as a loss and be risk-seeking.

\title{
Hypothesis Development
}

As discussed previously, prospect theory suggests that decision makers will be risk-seeking when a decision is framed as a loss. Additionally, personal involvement in a previous decision may influence the framing of a current decision. We hypothesize that decision makers are more likely to frame a decision as a gain or loss to themselves if their prior involvement in an earlier decision has caused them to become psychologically committed to a client's course of action started by their earlier decision. Their desire to justify a previously incorrect decision (or tax estimate) to themselves and/or their client should cause them to frame the current decision as a loss when their previous decision (or tax estimate) has resulted in their client facing a year-end tax payment situation. The framing of the decision as a loss will lead to risk-seeking behavior. Application of this analysis to the decision-making of tax preparers leads to the following hypothesis:

H1: Tax preparers who were actively involved in making estimated tax payment calculations for a client facing an unexpected tax payment upon filing his or her income tax return will take more aggressive tax reporting positions than tax preparers who were not actively involved in making estimated tax payment calculations for a client facing an unexpected tax payment upon filing his or her income tax return.

Hypothesis One addresses the question of whether tax preparers who were actively involved in making estimated tax payment computations for a client facing an unexpected tax payment at year-end will be more aggressive than those tax preparers who were not actively involved. What if the tax preparer's miscalculation causes an overpayment of taxes during the year, rather than an underpayment? Hypothesis Two addresses this issue.

Tax preparers should not be as likely to frame the current decision as a loss if the prior miscalculation results in an unexpected tax refund, rather than an unexpected tax payment. The tax preparer should have less need to justify his or her previous calculation to the client, who is not faced with making an unexpected payment. In addition, taking a more aggressive tax position will result in the tax preparer's previous estimate being even more incorrect by creating a larger refund. Despite personal involvement in the incorrect estimated payment calculation, we hypothesize that a tax preparer will frame an unexpected tax refund position as a gain.

Davis and Bobko (1986) found evidence that the level of escalation of commitment differs, depending on whether the outcome of the previous decision was positively or negatively framed. Davis and Bobko (1986) studied escalation of commitment in a government funding situation. The outcome of a job-training program was framed either negatively ("the program has failed to place $60.1 \%$ of all participants in either part-time or full-time jobs") or positively ("the program has placed 39.9\% of all participants in either part-time or full-time jobs"). Davis and Bobko (1986) found that continued commitment to a failing course of action was greater when subjects were personally responsible for the initial decision, but only when the outcome was framed negatively. Personal responsibility had no effect on continued commitment when the outcome was framed positively. There was less need to justify their previous decision when the results were framed positively. Applying this analysis to tax preparer decision-making, there should be less need for tax preparers to justify their previous calculation in an unexpected tax refund situation. Tax preparers are likely to frame clients' unexpected refunds positively, rather than negatively. Prospect theory predicts that decisions makers will be risk-averse when the refund is framed positively. Therefore, as discussed below, we predict that tax preparers who are psychologically committed to their client's year-end tax situation will be more risk-averse than tax preparers who are 
not psychologically committed.

Although we predict that non-psychologically committed tax preparers will be risk-averse, they do not have enough at stake in their client's year-end tax situation and therefore will not frame the situation and behave according to the value function of prospect theory. Instead, their level of risk aversion is predicted to be consistent with expected utility theory, and the utility function of non-psychologically committed tax preparers will be less steep than that of psychologically committed tax preparers. Because the slope of the value function under prospect theory is steeper than that under expected utility theory, tax preparers who are personally involved in calculating estimated tax payments should be more risk-averse than tax preparers who are not personally involved. This leads to the following hypothesis:

H2: Tax preparers who were actively involved in making estimated tax payment calculations for a client facing an unexpected tax refund upon filing his or her income tax return will take less aggressive tax reporting positions than tax preparers who were not actively involved in making estimated tax payment calculations for a client facing an unexpected tax refund upon filing his or her income tax return.

\section{Methodology}

A 2 x 2 design was employed, and participants were randomly assigned to one of four different experimental groups (referred to as groups A, B, C and D, respectively), as summarized in Figure 2.

\section{Figure 2 \\ Experimental Design}

\begin{tabular}{|c|c|c|c|}
\hline \multirow{4}{*}{$\begin{array}{l}\text { Tax Preparer } \\
\text { Involvement in } \\
\text { Calculating Estimated } \\
\text { Tax Payments }\end{array}$} & \multicolumn{3}{|c|}{ Withholding Status } \\
\hline & & $\begin{array}{l}\text { Payment Due } \\
\text { Condition }\end{array}$ & $\begin{array}{l}\text { Refund } \\
\text { Condition }\end{array}$ \\
\hline & Yes & Group A & Group B \\
\hline & No & Group C & Group D \\
\hline
\end{tabular}

\section{Independent Variables}

Participants were assigned to one of two tax preparer involvement conditions: personal involvement in calculating quarterly estimated tax payments and no personal involvement in calculating quarterly estimated tax payments. Prior studies have tested prospect theory by simply manipulating the wording of the case scenario. It would be difficult, however, to induce psychological commitment by having participants simply read a case scenario. In order to achieve a more effective psychological commitment inducement, participants actually made estimated payment computations.

In both conditions, participants were told that their client owns and operates a medium-sized C corporation engaged in building and selling manufactured homes. In the no personal involvement condition, participants were told that their client keeps good records and prepares his own estimated tax payment calculations. The tax preparer is involved only in preparing the client's income tax return at the end of the year, not in calculating quarterly estimated tax payments.

In the personal involvement condition, on the other hand, participants were told that their client is not interested in or knowledgeable of accounting and tax matters, and relies on the tax preparer extensively. The client provides the tax 
preparer with basic financial information and his thoughts on how he expects the business to do for the remainder of the year. The tax preparer calculates the amount of the required quarterly estimated tax payment and sends the estimated payment form and instructions to the client.

Participants in the personal involvement condition were first presented with basic information on the task they were asked to perform. They were told that it is January of the current year and that one of the most important tasks they perform for their client is computation of the amount of quarterly federal estimated tax payments their client should make during the current year. Participants were provided with three types of information: notes from a recent meeting with their client, financial information on the client (including an income statement and a balance sheet), and a Standard and Poor's Industry Forecast for the month of January. This forecast contains a summary of how the manufactured homebuilding industry is currently performing and a forecast of how the industry is expected to perform in the future. The entire experiment was administered via computer and participants were able to switch the computer between these three items of information and review each item as often as they desired. They were then asked to compute the amount of quarterly estimated tax payments their clients should make during the year and enter those amounts into the computer.

After the participants made their initial estimate, they were instructed to move to the next computer screen and were provided with additional information. They were told that it is now June of the current year and they have just finished a mid-year meeting with their client. One of the main objectives of the meeting was to determine whether their client's estimated tax payments should be revised. Participants were again provided with the three types of information and asked whether they would like to revise the quarterly estimated tax payments they set up in January. If participants choose to revise the estimated payment schedule, they were asked to provide the amount of the revised estimated payments. This second computation was designed both to make the experiment more realistic and to help induce psychological commitment by making the participants more involved in their client's tax situation.

Participants were also assigned to one of two year-end withholding status conditions: unexpected tax payment due upon filing their client's income tax return (payment condition) or unexpected tax refund available upon filing their client's income tax return (refund condition). The payment condition represents a loss situation. The refund condition represents a gain situation.

In the payment condition, participants were told that their client was expecting no additional tax payment or refund upon filing his return but, because of a mistake in calculating quarterly estimated tax payments, will actually have an unexpected balance due. Similarly, in the refund condition, participants were told that their client was expecting no additional tax payment or refund upon filing his return but, because of a mistake in calculating quarterly estimated tax payments, will actually receive an unexpected tax refund. The balance due (refund) figures are without considering the potential deduction of an ambiguous item. Thus, the balance due could be decreased, or the refund increased, by taking the ambiguous tax deduction.

Administering the experiment through the computer made the withholding status manipulation more realistic. Participants in the personal involvement condition were provided with different sources of information and asked to estimate their client's tax liability so that the client would have very little balance due or payable. Participants were then told that their estimate was too low (high) and their client is in an unexpected tax payment (refund) situation at year-end. This manipulation would not have been believable if presented in a paper booklet. The computer program used the actual tax number estimated by the participant and added (subtracted) a set amount to arrive at the unexpected tax payment (refund) position. This was designed to make the manipulation more believable than if it were presented in booklet form.

\section{Dependent Variable}

After making their final estimated payment computation, participants were informed of the total amount of taxes for the year and the amount of the year-end payment due (refund). They were then provided with a short case scenario containing an ambiguous tax deduction. The ambiguous tax deduction case scenario involved the issue of whether asbestos removal costs must be capitalized under Internal Revenue Code (IRC) section 263, or whether they may be deducted as a current expense under IRC section 162. There is no conclusive answer as to the proper tax 
treatment of asbestos removal costs.

After reviewing the ambiguous tax deduction scenario, participants were asked whether they would prepare and sign an income tax return containing a deduction of the asbestos removal costs. Their responses were measured on a 10point Likert-type scale and used as the dependent variable.

\section{Sample Characteristics}

A total of 198 experimental packages containing a computer diskette and instructions on how to complete the experiment were mailed to a contact person at the 18 different offices of the accounting firms that agreed to participate in the study. The contact person was instructed to randomly distribute the packages to participating members of their firms, collect the completed experimental materials within a stated period of time, and return all of the completed experimental packages to the researchers.

Because some accounting firms agreed to provide participants from more than one office location, the actual number of firms participating was 11 . These 11 participating firms were composed of six "Big 6" firms (now "Big 5"), three regional firms, and two local firms. The 18 participating offices were located in eight different cities and five different states, primarily in the midwest and southern regions of the United States.

A total of 107 experimental packages were received from 14 different offices (four offices failed to return the experimental packages). One hundred seven out of 198 experimental diskettes were returned, a response rate of 54\%. Three of the packages contained no data, so the number of respondents used in data analysis was 104.

Participants ranged in age from 22 to 54, with a mean age of 30.7. The average participant had 5.3 years of experience in public accounting, with 4.7 of those years spent specializing in tax. The range of experience levels was quite broad, ranging from individuals just beginning their accounting careers to individuals who had been in public accounting for over 25 years.

The participants came from a variety of educational backgrounds. Most of the participants (88.5\%) held a bachelors degree in accounting, although some had other business or nonbusiness degrees. In addition, over $20 \%$ of participants had a masters degree in tax. Fifty-two percent of the participants were male and $48 \%$ were female. The majority of participants $(62.5 \%)$ were CPAs.

A majority of the participants (62.8\%) practiced in "Big 6" (now "Big 5") accounting firms. The remainder came from regional $(24.5 \%)$ or local $(12.7 \%)$ firms. All levels of experience were represented. Approximately five percent of the participants classified themselves as partners, $25 \%$ as managers, $8 \%$ as supervisors, $26 \%$ as seniors, and $36 \%$ as staff accountants.

\section{Manipulation Check - Ambiguity of Tax Deduction}

The tax deduction case scenario presented to the participants was designed to be ambiguous. The issue of whether asbestos removal costs must be capitalized or can be expensed was used. The majority of tax practitioners agree that there is no conclusive answer as to the tax treatment of these costs. The case scenario summarized both sides of the issue in order to emphasize that there is no conclusive answer to the question of whether asbestos removal costs must be capitalized. The case scenario was pretested by several tax practitioners and revised in order to ensure that it was ambiguous.

After completing the experimental task, participants were asked whether asbestos removal costs: (1) are deductible, (2) must be capitalized, or (3) are an ambiguous tax issue, meaning it is not clear whether they are currently deductible or must be capitalized.

The result of a one-way ANOVA with the participants' assessment of the ambiguity of asbestos removal costs as the dependent variable was significant $(\mathrm{F}=12.99, \mathrm{P}=.0001)$. The majority (over $80 \%)$ of participants thought that 
the tax treatment of asbestos removal costs was ambiguous. In addition, the number of participants who thought asbestos removal costs were clearly deductible was about equal to the number who thought that asbestos removal costs must be capitalized. Therefore, the manipulation of the ambiguous tax case scenario was successful.

\section{Manipulation Check — Psychological Commitment}

Psychological commitment was measured by asking participants manipulation check questions after they completed the experimental material. The results of these measures of psychological commitment inducement are mixed. In the first psychological commitment manipulation check question, participants were asked: "How responsible did you feel for Smith Homebuilding ending up in an unexpected tax due (refund) position?" The argument supporting this measure of psychological commitment is that tax preparers who feel responsible for a client's year-end payment status will be more psychologically committed to that status than those who do not feel responsible. The result of a oneway ANOVA performed with the participants' answers to this question (as measured on a 10-point Likert-type scale) as the dependent variable was significant $(\mathrm{F}=4.54, \mathrm{p}=.005)$. Details regarding the response of participants in each of the four experimental groups are reported in Table 1. Participants who made estimated payment calculations (groups A and B) felt more responsible than participants who did not (groups C and D). This is consistent with an effective psychological commitment inducement. Participants in the tax refund condition who made estimated payment calculations (Group B) felt more responsible than participants in any of the other conditions. The cell means of groups A and B were not significantly different from one another. The cell mean of group B was significantly different than the cell means of groups $\mathrm{C}$ and D. Overall, these results provide moderate support for the effectiveness of the psychological commitment manipulation.

Table 1- Responsibility Participants Felt for Their Clients' Year-end Payment Status

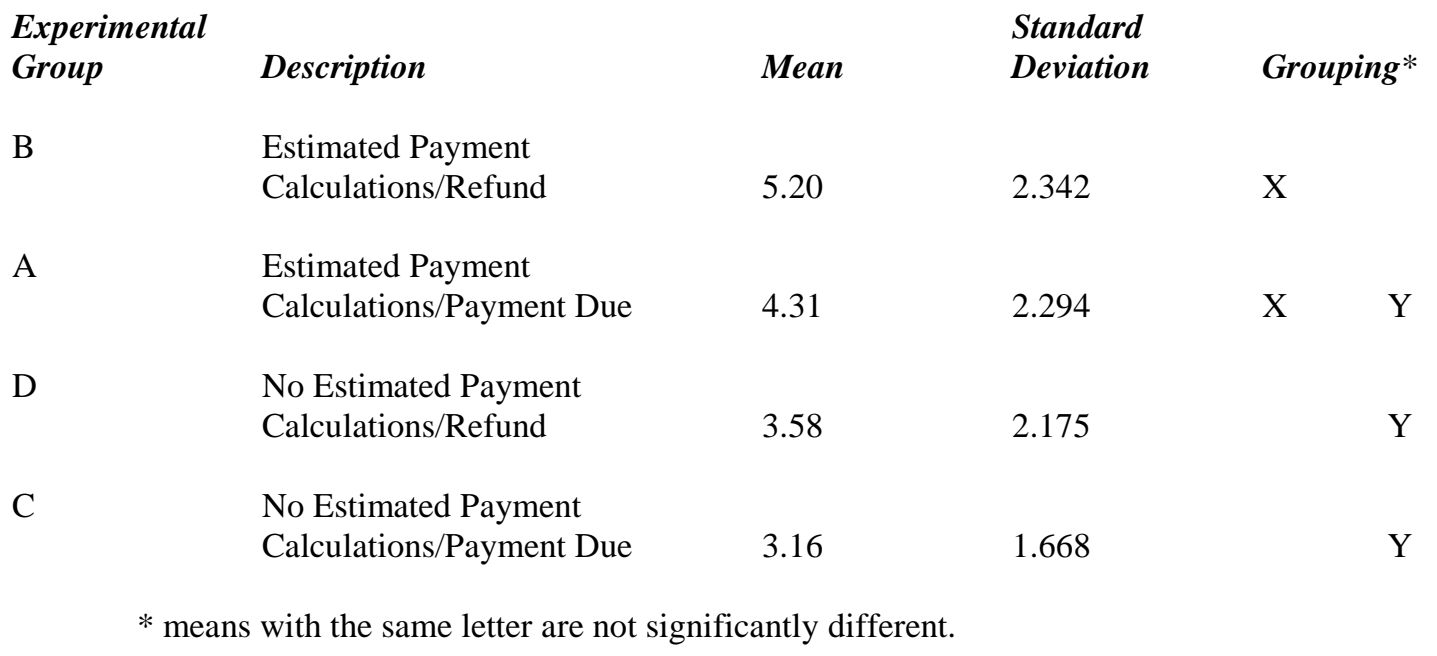

In the second psychological commitment manipulation check question, participants were asked: "How committed did you feel to assisting Smith Homebuilding in meeting its tax planning goals?" The result of a one-way ANOVA performed with participants' answers to this question (as measured on a 10-point Likert-type scale) as the dependent variable was not significant $(\mathrm{F}=0.85, \mathrm{p}=.471)$. As reported in Table 2, there was no significant difference in how participants in the four experimental groups responded to this question. The means of the four experimental groups ranged from 7.02 to 7.91. Participants in all four experimental groups indicated that they were reasonably committed to assisting Smith Homebuilding in meeting its tax planning goals. 


\section{Table 2 - Commitment of Participants to Assisting Clients in Meeting Their Tax Planning Goals}

\section{Experimental Condition}

A

B

$\mathrm{C}$

$\mathrm{D}$

\section{Description}

Estimated Payment

Calculations/Payment Due

Estimated Payment

Calculations/Refund

No Estimated Payment

Calculations/Payment Due

No Estimated Payment

Calculations/Refund
Mean*

7.71

7.39

7.91

7.02

\section{Standard Deviation}

2.203

2.073

1.885

2.563

* None of the cell means is significantly different from one another at a .05 level of significance.

\section{Manipulation Check — Gain or Loss Position}

The last manipulation check asked whether participants viewed themselves in a gain position or a loss position prior to considering the potential deduction of asbestos removal costs. Prospect theory predicts that decision makers will be risk-seeking in a loss situation and risk-averse in a gain situation. As discussed earlier, one of the possible reasons for the lack of results found in previous research in the tax preparer decision-making area is that tax preparers do not view themselves in a gain or loss position. It is the client's year-end gain or loss position, not the tax preparer's.

The result of the one-way ANOVA with participants' answers to this manipulation question as the dependent variable was significant $(\mathrm{F}=5.24, \mathrm{p}=.0242)$. Participants correctly framed the position they were in before considering the potential deduction of the asbestos removal costs $68.3 \%$ of the time. In other words, their framing of the situation they were in as a gain or a loss situation was consistent with the prediction of prospect theory $68.3 \%$ of the time. At first glance this manipulation appears successful. However, participants who framed their situation as a gain selected more aggressive tax reporting strategies than those who framed their situation as a loss. This difference in aggressiveness (6.42 to 5.18) is significant at the .05 level. This result is inconsistent with the predictions of prospect theory, in which decision makers in a loss situation are predicted to be more aggressive than decision makers in a gain situation. One possible explanation for this finding is that participants may not have properly understood what was meant by gain or loss position. Even when participants' answer to the gain/loss manipulation question indicated that they correctly framed the position they were in before considering the potential deduction of asbestos removal costs, their level of aggressiveness was inconsistent with the predictions of prospect theory.

\section{Analysis of Results}

Although random assignment of subjects to the four experimental conditions reduces the possibility of significant covariates, several demographic questions were included to provide an additional level of control. Possible covariates controlled for include the participants' age, sex, experience level, IRS audit experience, perception of the risk of IRS audit, and level of aggressiveness.

Two of the covariates, number of years experience in tax (TAXEXP) and gender (GENDER) were found to be significant. Therefore, ANCOVA was used to test the hypotheses, with TAXEXP and GENDER included as covariates.

Two other covariates, rank in accounting firm (RANK) and number of IRS audits worked on during career (AUDITS), were marginally significant. Both of these covariates were highly correlated with TAXEXP and thus were not included in data analysis reported below. Inclusion of these variables in the analysis did not significantly change the results. 
TAXEXP was transformed into a categorical variable for data analysis purposes. The median number of years of tax experience of the participants was three. Participants with three or less years of tax experience were included in the "low experience" group. Participants with four or more years of experience were included in the "high experience" group. Separating the low-experienced tax practitioners from the high-experienced tax practitioners by other methods did not significantly change the results.

\section{Results of ANCOVA}

The results of the ANCOVA with the tax reporting aggressiveness of the participants as the dependent variable (DV), VERSION (experimental group A, B, C or D) as the independent variable, and TAXEXP and GENDER as covariates, are reported in Table 3 . All possible interactions are also included in the model.

The overall model was not significant $(\mathrm{Pr}>\mathrm{F}=.1533)$. In addition, VERSION was not significant. Both covariates were moderately significant. None of the interactions was significant.

\section{Table 3 - Results of ANCOVA}

\begin{tabular}{|c|c|c|c|c|c|}
\hline Source & $D F$ & Sum of Squares & Mean Square & F-Value & $\operatorname{Pr}>\boldsymbol{F}$ \\
\hline Model & 12 & 110.2767 & 9.1897 & 1.46 & 0.1533 \\
\hline Error & 88 & 542.4293 & 6.2776 & & \\
\hline Correct Total & 100 & 658.8694 & & & \\
\hline Source & $D F$ & Type III SS & $M S$ & F-Value & $\operatorname{Pr}>\boldsymbol{F}$ \\
\hline VERSION & 3 & 20.9610 & 6.9870 & 1.11 & 0.3482 \\
\hline GENDER & 1 & 20.5547 & 20.5547 & 3.27 & $0.0738^{*}$ \\
\hline VERSION*GENDER & 3 & 2.8378 & 0.9459 & 0.15 & 0.9290 \\
\hline TAXEXP & 1 & 21.8267 & 21.8267 & 3.48 & $0.0656^{*}$ \\
\hline VERSION*TAXEXP & 3 & 13.0246 & 4.3415 & 0.69 & 0.5596 \\
\hline GENDER*TAXEXP & 1 & 0.9638 & 0.9639 & 0.15 & 0.6961 \\
\hline
\end{tabular}

* Significant at the .10 level

The means of VERSION are reported in Table 4. As can be seen, only experimental groups B and C were significantly different from each other in terms of aggressiveness, and only at the .09 level. The other groups were not significantly different from one another in terms of aggressiveness. Contrary to what was predicted, participants in group $\mathrm{C}$ were more aggressive than participants in group A.

Table 4 - Mean of DV in each of the experimental groups (VERSION)

\section{Experimental Group}

A

B

$\mathrm{C}$

$\mathrm{D}$

\section{Description}

Estimated Payment Calculations/Payment Due Estimated Payment Calculations/Tax Refund No Estimated Payment Calculations/Payment Due No Estimated Payment Calculations/Tax Refund

\section{$L S$ Mean}

5.83

$5.48^{*}$

$6.75^{*}$

6.34
Standard Error
LS Mean

0.556

0.534

0.544

0.506

*The cell means of experimental groups B and C are different from one another at the .09 level of significance. 
As reported in Table 5, males were more aggressive than females. The difference in adjusted means was significant at the .08 level. Table 6 shows that there was no interaction between GENDER and VERSION. Males were more aggressive than females in all experimental conditions.

Table 5 - Mean of DV by GENDER

$\begin{array}{lclll}\text { GENDER } & \text { Number } & \begin{array}{l}\text { Std Err } \\ \text { LSMean }\end{array} & \text { LSMean } & \text { Pr }>\text { T } \\ \text { Male } & 53 & 6.5884 & 0.3525 & 0.0738 \\ \text { Female } & 48 & 5.5927 & 0.4213 & \end{array}$

Table 6 - Mean of DV by GENDER and VERSION

\begin{tabular}{lllcl} 
& \multicolumn{4}{c}{ VERSION } \\
& $\boldsymbol{A}$ & $\boldsymbol{B}$ & $\boldsymbol{C}$ & D \\
Male & 6.068 & 6.038 & 7.459 & 7.023 \\
Female & 5.639 & 4.773 & 6.098 & 5.358
\end{tabular}

As reported in Table 7, experienced tax practitioners took more aggressive tax reporting positions than less experienced tax practitioners. This result was significant at the .07 level. There was no interaction between TAXEXP and VERSION. As can be seen in Table 8, more experienced tax practitioners were more aggressive than less experienced tax practitioners in all experimental conditions. This finding is consistent with several other studies in which tax preparer decision-making was found to be influenced by experience. The effect of experience appears to be robust to different client involvement and year-end payment status situations.

Table 7 - Mean of DV by TAXEXP

$\begin{array}{lcccc}\text { Experience Level } & \text { Number } & \text { LSMean } & \text { Std Err } & \text { Pr }>\text { T } \\ \text { High } & 43 & 6.6010 & 0.4272 & 0.0656 \\ \text { Low } & 48 & 5.5802 & 0.3430 & \end{array}$

Table 8 - Mean of DV by TAXEXP and VERSION

\begin{tabular}{lllll} 
& \multicolumn{4}{c}{ VERSION } \\
& $\boldsymbol{A}$ & $\boldsymbol{B}$ & $\boldsymbol{C}$ & $\boldsymbol{D}$ \\
High Experience & 6.068 & 6.038 & 7.459 & 7.023 \\
Low Experience & 5.639 & 4.773 & 6.098 & 5.358
\end{tabular}

\section{Results of Hypothesis Tests}

Hypothesis One predicted that tax preparers whose personal involvement in calculating a client's estimated tax payments resulted in their client facing an unexpected tax payment at year-end (group A) will take more aggressive tax reporting positions than tax preparers who were not involved in creating their client's year-end tax payment position (group C). As reported in Table 4, the difference in the cell means of experimental groups A and C was not significant. It is interesting to note, however, that the direction of the difference in cell means was opposite of what was expected. In the situation where a tax preparer's client was in an unexpected year-end tax payment position, participants not involved 
in calculating their client's estimated payment amounts were more aggressive than participants who were involved (6.75 to 5.83 ).

Hypothesis Two predicted that tax preparers whose personal involvement in calculating a client's estimated tax payments resulted in their client receiving an unexpected tax refund at year-end will take less aggressive tax reporting positions than tax preparers who were not involved in creating their client's year-end refund position. As reported in Table 4, the difference in cell means between experimental groups B and D was not significant (5.48 to 6.34). Thus, although the difference is in the predicted direction, Hypothesis Two was not supported.

Although Hypotheses One and Two were not supported, several interesting findings emerge from this study. First, consistent with what was predicted for psychologically committed tax preparers with a client in a year-end tax refund situation, participants in experimental group B were less aggressive than participants in any of the other three experimental groups, although the difference was only significant in the case of experimental group C. Also, gender and experience in tax were found to have an effect on tax preparer decision-making.

\section{Discussion of Research Results}

Neither Hypothesis One nor Hypothesis Two was supported. There are several possible reasons for this lack of results. The design of the study may not have been sufficient to capture the impact of prospect theory on tax preparer decision-making. Participants, even in experimental groups A and B, may not have viewed the client's year-end payment status as their (the tax preparer's) own gain or loss position. The inconclusive results reached in both the psychological commitment and gain/loss position manipulation check questions support this possibility. As reported previously, participants did not behave in a manner consistent with the predictions of prospect theory in those cases where their answer to the gain/loss manipulation question indicated that they correctly framed the decision as a gain or loss position, respectively. It is possible that participants may not have understood the question. Thus, it is possible that participants not properly framing their client's year-end payment position as a gain or loss position caused the inconclusive results.

The inconclusive results also may have been caused by an ineffective psychological commitment inducement. It is possible that psychological commitment causes tax preparers to frame situations and behave in a manner consistent with the predictions of prospect theory in practice, and that the lack of results is due to the difficulty of inducing psychological commitment in an experimental setting.

Another possible reason for the lack of results in this study, and one that has been suggested by prior researchers in this area, is the possibility that "prospect theory is not a powerful theory for understanding decision making in a tax context" (Newberry et al. 1993, p. 450).

\section{Conclusion}

This research makes a contribution to the literature by introducing psychological commitment as a moderating variable in the application of prospect theory to tax preparer decision-making. This research, however, failed to find evidence in support of either hypothesis. The study does provide some evidence that the tax reporting aggressiveness of tax preparers is influenced by various factors, including client year-end payment status, tax preparer involvement in estimated payment calculations, gender, and tax experience of tax preparers. The main results of the study, however, are inconsistent with prospect theory and difficult to interpret.

Given the inconclusive results of this study, there is still much uncertainty regarding how, or if, prospect theory can be applied to tax preparer decision-making. Further research is needed before prospect theory can be successfully applied to assist tax preparers in their decision-making. The inconclusive results of this research add evidence to the suggestion that prospect theory may not be an appropriate theory for studying tax preparer decision making. 


\section{References}

1. Brockner, J. 1992. The escalation of commitment to a failing course of action: Toward theoretical progress. Academy of Management Review 17: 39-61.

2. Chang, O. 1995. An investigation of taxpayers' framing behavior. Advances in Taxation 7: 25-42.

3. Chang, O., D. Nichols, and J. Schultz. 1987. Taxpayer attitudes toward tax audit risk. The Journal of Economic Psychology 8: 299-309.

4. Davis, M., and P. Bobko. 1986. Contextual effects on escalation processes in public sector decision making. Organizational Behavior and Human Decision Processes 37: 121-138.

5. Duncan, W., D. LaRue, and P. Reckers. 1988. An empirical examination of the influence of selected economic and noneconomic variables on decision-making by tax professionals. Advances in Taxation 2: 91-106.

6. Dusenbury, R. 1994. The effect of prepayment position of individual taxpayers' preferences for risky taxfiling options. The Journal of the American Taxation Association: 16 (1): 1-16 .

7. Kahneman, D., and A. Tversky. 1979. Prospect theory: An analysis of decision under risk. Econometrica 47: 263-291.

8. Kahneman, D., and A. Tversky. 1981. The framing of decisions and the psychology of choice. Science 211: 453-458.

9. LaRue, D., and P. Reckers. 1989. An empirical examination of the influence of selected factors on professional tax preparers' decision processes. Advances in Accounting 7: 37-50.

10. Newberry, K., P. Reckers, and R. Wyndelts. 1993. An examination of tax practitioner decisions: The role of preparer sanctions and framing effects associated with client condition. Journal of Economic Psychology 14: 439-452.

11. Sanders, D., and R. Wyndelts. 1989. An examination of tax practitioners' decisions under uncertainty. Advances in Taxation 2: 41-72.

12. Schadewald, M. 1989. Reference point effects in taxpayer decision making. The Journal of the American Taxation Association 11 (1): 68-84.

13. Schepanski, A., and D. Kelsey. 1990. Testing for framing effects in taxpayer compliance decision. The Journal of the American Taxation Association 12 (2): 60-77.

14. Schisler, D. 1994. An experimental examination of factors affecting tax preparers' aggressiveness - a prospect theory approach. The Journal of the American Tax Association 16 (2): 124-142.

15. Schisler, D. 1996. An experimental examination of the effects of withholding positions and tax preparer recommendations on taxpayer aggressiveness. Advances in Taxation 8: 149-173.

16. Staw, B. 1976. Knee-deep in the big muddy: A study of escalating commitment to a course of action. Organizational Behavior and Human Performance 16: 27-44.

17. von Neumann, J., and O. Morgenstern. 1944. Theory of Games and Economic Behavior. Princeton, NJ: Princeton University Press.

18. White, R., P. Harrison, and A. Harrell. 1993. The impact of income tax withholding on taxpayer compliance: Further empirical evidence. The Journal of the American Taxation Association 15 (2): 63-78.

19. Whyte, G. 1986. Escalating commitment to a course of action: A reinterpretation. Academy of Management Review 11: 311-321. 
Notes 